\title{
Esmark elastoplasty for bleeding ventricular assist device outflow graft associated with severe coagulopathy
}

\author{
Daniel J. DiBardino, MD, and Gregory S. Couper, MD, Boston, Mass
}

Severe coagulopathy is a common entity during biventricular assistance and is particularly difficult to deal with when using bivalirudin as an anticoagulant. Resultant severe coagulopathy can causes relentless bleeding, even from needle holes and graft interstices. We report the use of Esmark (Advanced Medical Designs, Marietta, Ga) as an elastoplastic bandage to tamponade bleeding from a ventricular assist device outflow graft.

\section{CLINICAL SUMMARY}

A 34-year-old woman with a history of right lower extremity osteosarcoma had adriamycin-induced cardiomyopathy. After long-term clinical stability, pregnancy resulted in decompensation, premature loss of pregnancy, and placement of a Tandemheart (Cardiac Assist, Inc, Pittsburgh, $\mathrm{Pa}$ ) percutaneous left ventricular assist device (LVAD). After improvement and weaning from the device, hemodynamic decompensation again occurred, prompting redo percutaneous LVAD placement and surgical referral for long-term bridge to transplantation therapy. Biventricular assistance was deemed necessary. Secondary to heparin-induced thrombocytopenia, bivalirudin was used for cardiopulmonary bypass, with activated clotting times reaching as high as 700 seconds. A Heartmate II Axial flow device (Thoratec Corp, Pleasanton, Calif) was placed in the left ventricle-to-aorta configuration. The Tandemheart pump previously used as the percutaneous LVAD was recycled on the operative field and used as a right ventricular assist device with percutaneous right atrial inflow and outflow to the pulmonary artery.

Despite discontinuing the bivalirudin near the conclusion of the procedure, the patient had a severe unrelenting coagulopathy with consumption of products, factors, and platelets. Repeated packing of the chest resulted in little improvement because maximum transfusion therapy was delivered at the fastest rate possible. A total of 70 units of packed red blood cells, 94 units of fresh frozen plasma, 19 units of platelets,

From the Department of Cardiac Surgery, Brigham and Woman's Hospital, Harvard Medical School, Boston, Mass.

Disclosures: None.

Received for publication Aug 24, 2009; revisions received Sept 24, 2009; accepted for publication Sept 28, 2009; available ahead of print Dec 11, 2009.

Address for reprints: Daniel J. DiBardino, MD, Cardiac Surgery, Brigham and Woman's Hospital, 15 Francis St, Boston, MA 02215 (E-mail: Daniel. DiBardino@gmail.com).

J Thorac Cardiovasc Surg 2010;139:1658-9

$0022-5223 / \$ 36.00$

Copyright (c) 2010 by The American Association for Thoracic Surgery doi:10.1016/j.jtcvs.2009.09.052 packs and 10 units of cryoprecipitate were given during the course of the operation. Three doses of Factor VII were ultimately approved by the blood bank and were given with a slight improvement. On the last re-exploration, most of the blood loss appeared to be coming from the LVAD outflow graft, which was bleeding through the interstices of the Dacron, despite aggressive correction of the hematology derangements. An Esmark bandage was brought onto the field and cut into strips. Applying constant pressure during application, the strips were used as an elastoplastic compression dressing to the LVAD outflow graft (Figure 1). As can be seen in Figure 1, straight hemostats were used to maintain temporary compression while a running 4-0 Prolene (Ethicon, Inc, Somerville, NJ) longitudinal suture line was used to permanently fix the tension. This resulted in cessation of bleeding to the point at which the patient was then able to be packed with an open chest and transported to the intensive care unit. At planned re-exploration on postoperative day 2 , only a small amount of residual clot remained in the mediastinal chest tubes.

\section{DISCUSSION}

Esmark bandages are marketed in part as providing " $\max$ imum and consistent pressure to extremities for exsanguination prior to surgery" and are thought to provide "consistent elongation for optimum compression." 1 There are references in the peer-reviewed literature regarding use of Esmark for such extremity applications. ${ }^{2-5}$ In patients undergoing cardiac surgery, we have taken advantage of Esmark's inert

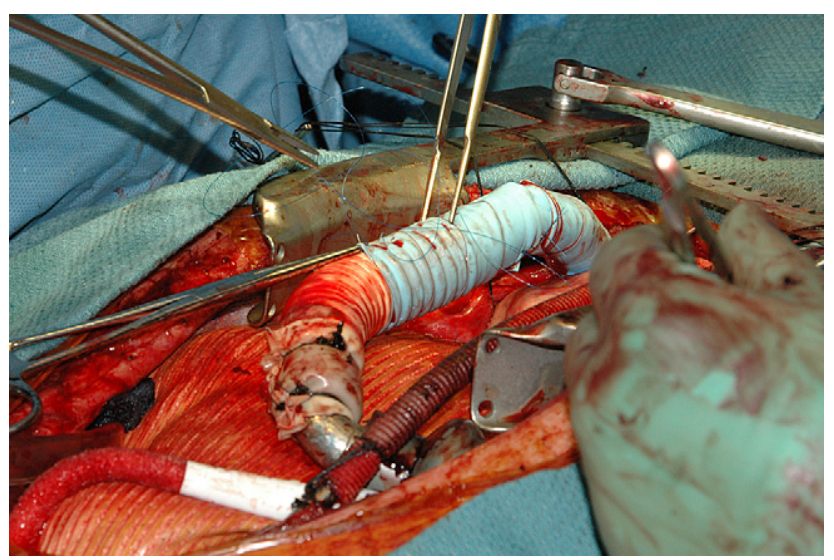

FIGURE 1. Esmark bandage cut into strips and used as an elastoplastic compression bandage to arrest unrelenting hemorrhage through the left ventricular assist device outflow graft. A straight hemostat holds tension on the wrap while the running Prolene suture line is completed. 
properties and sterile packaging to configure temporary sternotomy dressings when wounds are left open after surgical intervention, although no reference for this use is found.

Severe coagulopathy is common after biventricular assist device placement and is especially malignant after cardiopulmonary bypass with heparin alternatives. We have previously used several methods to arrest hemorrhage from ventricular assist device connections and grafts in the face of such coagulopathy and platelet dysfunction. One method is to apply strips of Penrose rubber drains with circumferentially tied silk sutures as compression bandages for a tamponade effect. Our experience is that this provides hemostasis, particularly at sites of connection between the metal ventricular assist device outflow and graft material. For bleeding graft interstices, we have had success with longitudinally splitting a second graft one size larger, sealing it with surgical adhesive, and applying this on top of the bleeding graft.

Neither technique worked in this case. Because Esmark is available in our operating room, it seemed a natural extension to apply its consistent compression qualities in the form of an elastoplastic dressing for a bleeding outflow graft in the face of severe coagulopathy. In this configuration it seemed to provide effective and consistent pressure and can be considered for compression in situations other than extremity surgery.

We would like to acknowledge Rene Dekkers from Brigham and Woman's Hospital perfusion services for his inspiration over the years.

\section{References}

1. Latex-Free Esmark Bandages Web site. Available at: http://www.fulflex.com/ industries-served/medical-and-healthcare/esmark/default.html.

2. Miles RH, Kollpainter RE, Riveron FA, Johnkoski JA. The pneumatic tourniquet technique for endoscopic radial artery harvest. J Card Surg. 2004;19:495-8.

3. Grebing BR, Coughlin MJ. Evaluation of the Esmark bandage as a tourniquet for forefoot surgery. Foot Ankle Int. 2004;25:397-405.

4. Tarver HA, Oliver SK, Ramming GJ, Englemann B. Techniques to maintain a bloodless field in lower extremity surgery. Orthop Nurs. 2000;19:65-73.

5. Anonymous. Excessive cornstarch powder on latex (Esmark) bandages. Health Devices. 1996;25:150

\title{
Bronchoscopic transesophageal ultrasound-guided needle aspiration: An alternative to the conventional transesophageal ultrasound-guided needle aspiration technique
}

\author{
Masahide Oki, MD, ${ }^{\mathrm{a}}$ Hideo Saka, MD, ${ }^{\mathrm{a}}$ Chiyoe Kitagawa, MD, ${ }^{\mathrm{a}}$ and Shinji Sato, MD, ${ }^{\mathrm{b}}$ Nagoya and Handa, \\ Japan
}

The real-time ultrasound-guided needle aspiration technique through the airway (endobronchial ultrasound-guided transbronchial needle aspiration [EBUS-TBNA]) or esophagus (endoscopic ultrasound-guided fine needle aspiration [EUS-FNA]) has been reported to be an accurate and minimally invasive technique for evaluation of hilar/mediastinal lesions. ${ }^{1-3}$ Both techniques have been reported to be complementary because some accessible regions differ from each other. ${ }^{1-3}$ However, the combination of these procedures, which require separate equipment or examiners, is much more complex than either procedure by itself.

\footnotetext{
From the Department of Respiratory Medicine, ${ }^{\text {a }}$ Nagoya Medical Center, Nagoya and the Department of Respiratory Medicine, ${ }^{\mathrm{b}}$ Handa City Hospital, Handa, Japan. Disclosures: None.

Received for publication Sept 5, 2009; accepted for publication Sept 28, 2009; available ahead of print Nov 30, 2009

Address for reprints: Masahide Oki, MD, Department of Respiratory Medicine, Nagoya Medical Center, 4-1-1 Sannomaru, Naka-ku, Nagoya 460-0001, Japan (E-mail: masahideo@aol.com).

J Thorac Cardiovasc Surg 2010;139:1659-61

$0022-5223 / \$ 36.00$

Copyright (c) 2010 by The American Association for Thoracic Surgery

doi:10.1016/j.jtcvs.2009.09.054
}

The mechanism of EBUS bronchoscopes is similar to that of EUS endoscopes, and therefore bronchoscopic transesophageal ultrasound-guided fine-needle aspiration might be feasible. ${ }^{4}$ We herein describe a patient with a mediastinal lymph node metastasis who did not undergo EBUSTBNA but whose condition was successfully diagnosed by means of EUS-FNA with an EBUS bronchoscope.

\section{CLINICAL SUMMARY}

A 66-year-old man with a mediastinal abnormality on positron emission tomographic scanning was referred to our hospital for bronchoscopic evaluation. He had undergone right middle lobectomy because of lung cancer (adenocarcinoma) 7 years before and left upper segmentectomy because of lung cancer (adenocarcinoma) 2 years earlier. A follow-up computed tomographic scan showed a small lymph node in the left paratracheal mediastinal region (Figure 1, $A$ ), and subsequent fluorodeoxyglucose positron emission tomographic scanning revealed a hypermetabolic lesion (Figure 1, B).

Bronchoscopy was performed after achievement of local anesthesia and conscious sedation. The endobronchial 